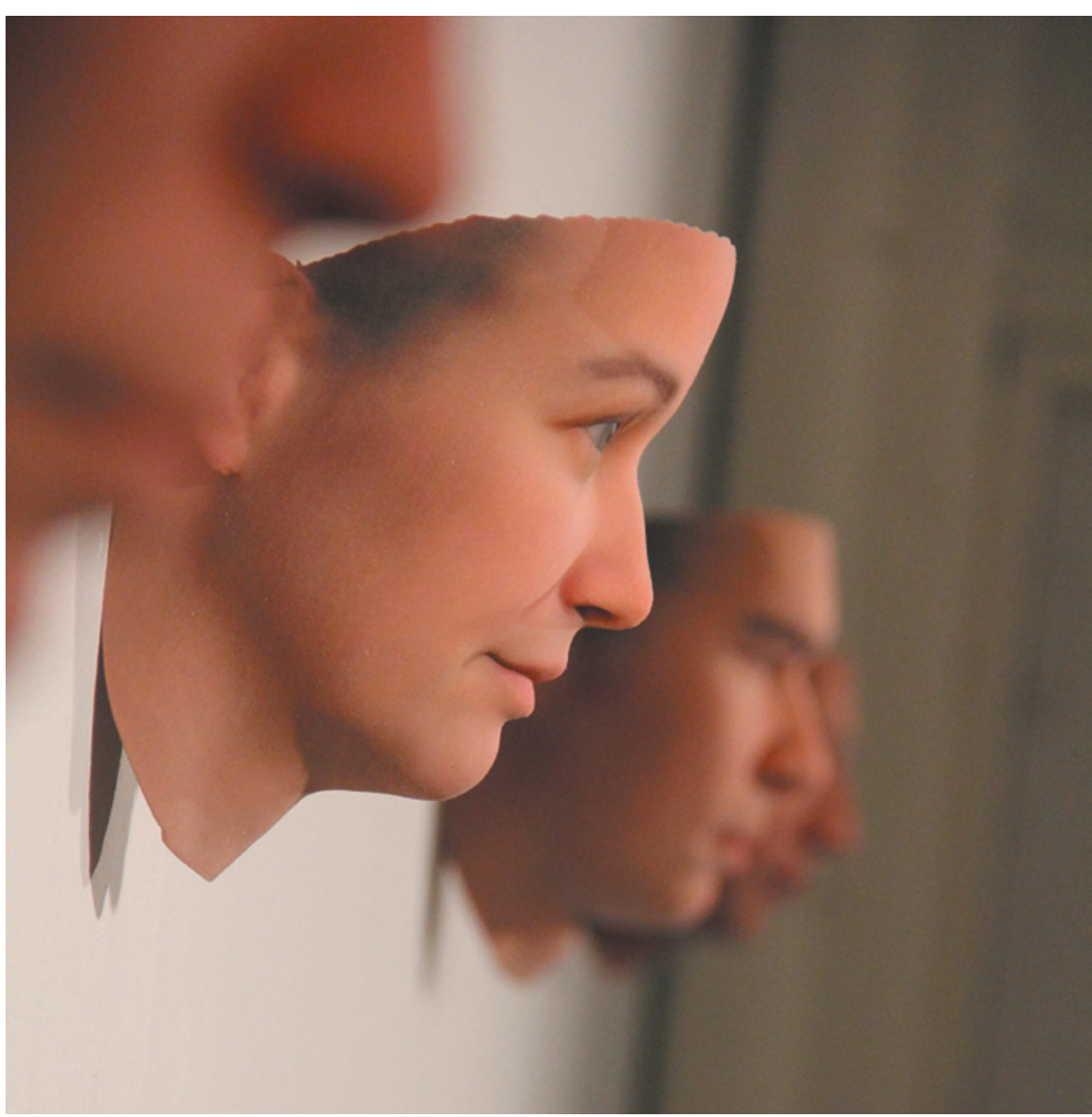

In Stranger Visions, a work in Grow Your Own, Heather Dewey-Hagborg creates portraits from found DNA.

SYNTHETIC BIOLOGY

\section{The second creation}

\section{Anthony King finds himself on some of the wilder shores of synthetic biology at Dublin's Science Gallery.}

$\mathrm{P}$ eering into a fridge, I am invited to sniff a cream cheese labelled "Christina". It is crafted from milk and starter cultures sampled from someone's skin. There are three more, each with a unique set of microbes from a different person: cheesy doppelgängers that will never, in our pasteurized world, reach the table.

Selfmade is the work of synthetic biologist Christina Agapakis and smell provocateur Sissel Tolaas, who are making the human microbiome tangible and highlighting a potential conflict between our antibacterial present and a future filled with engineered bacteria. Agapakis and Tolaas are members of Synthetic Aesthetics, a project run by the University of Edinburgh, UK, and Stanford University in California, to research the borders between art and synthetic biology. Theirs is one exhibit in the Dublin Science Gallery's Grow Your Own ... Life After Nature show,
Grow Your Own ... Life After Nature Science Gallery, Trinity College, Dublin. Until 19 January 2014

which explores genetic engineering.

The show, which is split into sections labelled 'Life', 'Society' and 'Machines', offers a brew of utopian and dystopian views. There are also chances for visitors to 'grow their own' life form in a biolab and, as usual in this venue, there is an emphasis on citizen engagement with science.

In the Life section, I ponder Escherichia coli that has been modified to smell of banana, and then an exhibit exploring the idea that a woman could carry the fetus of a rare dolphin. In Society, upstairs, I discover how to 'biohack' the first commercially available genetically modified flower - the blue Moondust carnation - by using basic plantculture methods to re-root the cut flowers and plant them to rejoin the carnation gene pool. This do-it-yourself project raises questions about the ownership of life, including the moral question of whether the hacked plants should be released.

Artist David Benqué gives the heated debate on genetically modified organisms a novel twist. In his installation The New Weathermen, fictional environmental activists use madcap synthetic-biology schemes to fight corporate biotechnology interests. The exhibit takes the form of their scaled-down rigs, such as a "self-inflating antipathogenic membrane pump" and an "autonomous seed disperser", with which Benqués anarchists spray golf-course grass modified for herbicide tolerance to spread their own open-source super-grass.

In the Machines section sits a piece by design futurist Natsai Audrey Chieza. Chieza collaborates with microbiologist John Ward at University College London to find soil bacteria that produce pigments suitable for dyeing textiles. In Faber Futures - a reference to the Latin for 'to create' Petri dishes are filled with Streptomyces bacteria from soils in which different herbs were growing. Chieza removed specific colonies displaying various colours to dye silk scarves: bacteria isolated from around tarragon yielded blood-red hues; spearmint, deep purple; and oregano, light blue to navy. "Sometimes the most beautiful colours emerge if a contaminant comes in," says Chieza.

Show curator and exhibitor Alexandra Daisy Ginsberg's Designing for the Sixth Extinction in the Society section is a naturalistic 'photo' of a verdant forest inhabited by strange, digitally inserted creatures such as a roving seed-dispersal device to increase plant biodiversity. Patented life forms released into the wild to assist endangered species, they are constructed using an expanded DNA code of six bases rather than the usual four. This produces non-biodegradable proteins, which are more robust. "It sets up a future where we could preserve and maintain nature using synthetic biology," says Ginsberg.

Most people know little about synthetic biology, despite the best intentions of leaders in this field such as Craig Venter and George Church. "The foundations are being laid now," Ginsberg says. "That is why it's so important that people understand what it is and the many different directions it could go in." Grow Your Own urges us to imagine many possible engineered futures - positive and negative, created with or without our consent - and challenges us to engage with the research by joining in. In January, visitors will even be able to use DNA to nudge E. coli into fluorescing in the exhibition biolab.

Anthony King is a writer based in Dublin. e-mail:anthonyjking@gmail.com 